\title{
Evaluation of the effect of high dose intravenous vitamin C on delayed allograft function in deceased donor kidney transplantation: a preliminary report
}

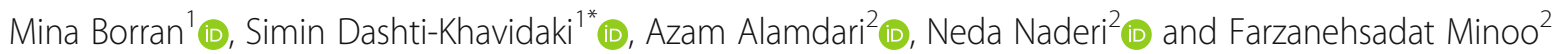

\begin{abstract}
Background: Delayed graft function (DGF) can affect short- and long-term allograft outcomes in kidney transplant recipients. One of the pathophysiological pathways in the occurrence of DGF is ischemia-reperfusion injury (IRI). High dose intravenous vitamin C has proven efficacy in decreasing IRI consequences. Accordingly, we designed this study to assess the effect of high dose intravenous vitamin C on the incidence and duration of DGF.

Methods: This is a pilot, single-center, double-blinded, randomized, placebo-controlled trial. In the treatment group, kidney transplant recipients received vitamin C infusion at the dose of $70 \mathrm{mg} / \mathrm{kg}$ diluted in $0.45 \%$ saline, and in another study arm, only the diluent solution was administered. Data regarding allograft function and other clinical information was recorded.

Results: This preliminary study on 19 patients ( 9 cases in the vitamin $C$ and 10 cases in the placebo group) showed that after administration of single, high dose vitamin $C$ the incidence of DGF was not significantly different between the groups, but the duration of DGF was substantially shorter in the vitamin $C$ group than the placebo group (7.33 \pm 5.68 versus $19.66 \pm 0.57$ days; $P=0.02$ ). Acute rejection episodes were more seen in the vitamin $C$ group than in the placebo group. Although this data was not statistically significant $(P=0.37)$, it led to the termination of the study.
\end{abstract}

Conclusion: A high dose of intravenous vitamin C before allograft implantation was effective in decreasing DGF duration but not DGF incidence.

Trial registration: The trial was registered in the Iranian registry of clinical trials encoded IRCT20100111003043N13 on June 24, 2019.

Keywords: Ascorbic acid, Delayed graft function, Kidney transplantation, Vitamin C

\footnotetext{
* Correspondence: dashtis@sina.tums.ac.ir

${ }^{1}$ Faculty of Pharmacy, Tehran University of Medical Sciences, P.O.Box

1417614411, Tehran, Iran

Full list of author information is available at the end of the article
}

(c) The Author(s). 2020 Open Access This article is licensed under a Creative Commons Attribution 4.0 International License, which permits use, sharing, adaptation, distribution and reproduction in any medium or format, as long as you give appropriate credit to the original author(s) and the source, provide a link to the Creative Commons licence, and indicate if changes were made. The images or other third party material in this article are included in the article's Creative Commons licence, unless indicated otherwise in a credit line to the material. If material is not included in the article's Creative Commons licence and your intended use is not permitted by statutory regulation or exceeds the permitted use, you will need to obtain permission directly from the copyright holder. To view a copy of this licence, visit http://creativecommons.org/licenses/by/4.0/. The Creative Commons Public Domain Dedication waiver (http://creativecommons.org/publicdomain/zero/1.0/) applies to the data made available in this article, unless otherwise stated in a credit line to the data. 


\section{Introduction}

Delayed graft function (DGF) is one of the early complications after kidney transplantation. The need for undergoing dialysis therapy within the first week after transplantation is the most practical definition of DGF. However, there are different other descriptions in the literature, so reported prevalence rates are also different [1, 2]. So far, no drug has been approved for complete prevention or full recovery of DGF; hence, it is still an area of active research. Despite advances in renal transplantation and subsequent drug therapy, the incidence of DGF has not decreased, and in fact, there was an increase in DGF incidence over the period 1998-2018 [2]. The possible reason is the use of the non-ideal organ, owing to the growing need for kidney transplantation and organ shortage [2, 3]. DGF occurrence affects the short- and long-term transplantation outcomes, graft rejection, and patients' and organs' survival [4]. The most important risk factors for DGF occurrence include deceased donor, higher donor's serum creatinine and age, donation after cardiac death, recipient's body mass index (BMI), and cold ischemic time [5]. Therapeutic interventions to reduce the incidence of DGF are administered either before or after transplant surgery on harvested organ or recipient. The use of anti-inflammatory, vasodilator, and immunosuppressant drugs have been the most common studied treatments on transplant recipients [2].

Different immunological and non-immunological processes are involved in the development of DGF. One of the potential pathophysiological pathways in the occurrence of DGF is ischemia-reperfusion injury (IRI) [4]. Anaerobic metabolism and cellular acidosis occur during ischemia. Ischemic state intensifies the production of reactive oxygen species (ROS), such as superoxide, hydrogen peroxide, and hydroxyl radicals $[6,7]$. At the reperfusion phase, increased oxygen supply and normalization of extracellular $\mathrm{pH}$ can eventuate calcium overload in the cytoplasm and mitochondria and subsequent damage to cellular structures. IRI eventually causes acute tubular necrosis and activation of the innate and adaptive immune system [6]. Drugs with antioxidant and anti-inflammatory properties have shown efficacy in reducing IRI consequences in different studies [8].

Vitamin C (ascorbic acid) is a multifunctional micronutrient. It acts as an antioxidant, anti-inflammatory, and cofactor of biological enzymes [9]. There is a growing body of pre-clinical and clinical studies using highdose intravenous vitamin $\mathrm{C}$ to minimize IRI in the myocardium and brain [10]. Vitamin $C$ has been useful in diminishing IRI in the experimental kidney model [11]. The role of high-dose intravenous vitamin $\mathrm{C}$ also has been established in the treatment of severe sepsis [12]. Sepsis and IRI have similar pathophysiology, in which large amounts of ROS can impair endothelial function, cause cellular damage and organ dysfunction [10]. Accordingly, given the positive effect of vitamin $C$ on sepsis, it seems that high-dose intravenous vitamin $C$ may also be useful in other forms of IRI.

The safety and efficacy of vitamin $\mathrm{C}$ in solid organ transplantation have been examined in several studies. Positive effects of vitamin $\mathrm{C}$ in this patient population include the prevention of transplant-induced atherosclerosis in heart transplant patients [13], improvement of endothelial dysfunction in renal transplant patients [14], improvement of creatinine clearance in renal transplant patients $[15,16]$; and decrease low-density lipoprotein cholesterol oxidation in renal transplant recipients on tacrolimus [17]. In a clinical study, $75 \mathrm{mg}$ oral vitamin $\mathrm{C}$ in combination with oral $\mathrm{N}$-acetyl cysteine did not reduce the risk of DGF [18]. According to the present findings, the effective dose to reduce IRI is at least $3 \mathrm{~g}$ of intravenous vitamin C [10]; so ineffectiveness in that study (24) can be justified by low dose and oral administration. Most studies using high doses of vitamin $C$ have reported no side effects more than the placebo group [19]. However, there have been reports of kidney stones, hypokalemia, fatigue, hemolysis in glucose 6 phosphate dehydrogenase (G6PD) deficient patients, and unpleasant sensations after vitamin C injection [20]. Hemolysis in patients with G6PD deficiency is one of the uncommon side effects of vitamin $C$. There are several cases of hemolysis in G6PD-deficient individuals with 3 to more than $80 \mathrm{~g}$ vitamin $\mathrm{C}$ [21]. Justification for this effect is the reduction in the amount of reduced glutathione in the presence of vitamin $\mathrm{C}$ in red blood cells [22]. On the other hand, Paul E. Marik, known for his vitamin $\mathrm{C}$ sepsis cocktail, stated in an editorial letter that vitamin $C$ in a dose of about $6 \mathrm{~g}$, not only does not increase hemolysis but also has a protective effect against it [23]. Otherwise, severe vitamin $C$ deficiency is associated with hemolysis [24].

Given the significant role of IRI in DGF pathophysiology and evidences on efficacy of high dose intravenous vitamin $\mathrm{C}$ (at least $3 \mathrm{~g} / \mathrm{dose}$ ) in reducing the consequences of IRI [10], and also evidences of vitamin C deficiency among transplant recipients [25], this preliminary study was designed to assess the effect of high dose intravenous vitamin $\mathrm{C}$ on incidence and duration of DGF among kidney transplant recipients.

\section{Materials and methods}

\section{Design and population}

This pilot, single-center, double-blinded, randomized controlled trial was performed in Imam Khomeini Hospital Complex affiliated to Tehran University of Medical Sciences from June to October 2019. Patients aged 14 years and over who were candidates for the first kidney transplantation from a deceased donor were included with 
written informed consent. We excluded patients with hemochromatosis, end-stage kidney disease due to hyperoxaluria, multiple organ transplantation, history of favism, and preemptive kidney transplantation. The study protocol was approved by the local ethics committee of Tehran University of Medical Sciences (IR.TUMS.TIPS.REC.1398.007). Also, it was registered in the Iranian registry of clinical trials encoded IRCT20100111003043N13.

\section{Treatment}

Patients were allocated to two study arms of vitamin C or placebo by block randomization with a block size of four. Patients in the treatment group received intravenous vitamin C $(500 \mathrm{mg} / 5 \mathrm{ml}$ ampoules, DarouPakhsh Pharmaceutical company, Iran) at a dose of $70 \mathrm{mg} / \mathrm{kg}$ within $1 \mathrm{~h}$ of transplantation. Vitamin $\mathrm{C}$ was diluted in $250 \mathrm{ml}$ of $0.45 \%$ sodium chloride solution and infused for $1 \mathrm{~h}$. In the placebo group, the same volume of saline solution was infused in the same manner. Supraphysiologic blood concentrations are needed for the effectiveness of vitamin $\mathrm{C}$ to reduce the consequences of IR injury. This is only feasible with the administration of intravenous vitamin $\mathrm{C}$ for a minimum dose of $3 \mathrm{~g} /$ day. It can be provided by fixed doses [10] or weight-based doses in the range of $50-200 \mathrm{mg} / \mathrm{kg}$ [26]. Considering the dose of $70 \mathrm{mg} / \mathrm{kg}$, all patients received a sufficient dose of vitamin $C$ based on both methods. The half-life of parenteral vitamin $C$ is short, so vitamin $C$ bolus will attain higher plasma levels for only a short period. Transplant recipients from deceased donors in this study were pre-op admitted only a few hours before transplantation surgery. Often a dialysis session is also performed during these hours. According to vitamin $\mathrm{C}$ uptake during dialysis, the time interval between the end of the dialysis session and transplant surgery is selected. At this time, it was possible to inject the mentioned dose of parenteral vitamin $\mathrm{C}$ within $1 \mathrm{~h}$. Therefore, the intravenous infusion was selected as the prescribing method during the final hour before surgery.

Patients in both study arms received the same immunosuppression regimen according to the local protocol. All patients received rabbit anti-thymocyte globulin (rATG) and methylprednisolone as induction therapy. The maintenance regimen consists of oral tacrolimus, mycophenolate sodium, and prednisolone. To opportunistic infection prophylaxis, all patients received trimetho$\mathrm{prim} / \mathrm{sulfamethoxazole,} \mathrm{ganciclovir} \mathrm{or} \mathrm{valganciclovir,} \mathrm{and}$ clotrimazole.

\section{Definition}

The primary endpoints of the study were comparisons of DGF incidence and duration between the two arms. In this study, three criteria were used to define DGF including the need for dialysis within the first week of transplantation, a daily decrease of less than $10 \%$ in serum creatinine concentration during three consecutive days within the first week after transplantation, or urine output of less than $300 \mathrm{~mL}$ within $6 \mathrm{~h}$ after transplantation. DGF duration was defined as the number of days from the transplantation to the last dialysis session or three consecutive days with more than $10 \%$ decrease in serum creatinine concentration. Secondary outcomes were as follows: estimated glomerular filtration rate (eGFR) using the MDRD equation at discharge and 3 months after the transplant, hospitalization duration, and rejection episodes during the first 3 months of transplantation. Protocol (surveillance) biopsies are not performed at our center. In the case of the indicated biopsies, the pathologic results were fully recorded. In biopsy-proven acute rejection (BPAR) cases, the Banff criteria have been used to evaluate transplant rejection. Cases of clinically suspected transplant rejection have been reviewed and documented based on clinical conditions and response to treatment.

\section{Follow-up}

We visited enrolled patients daily during the hospital stay. Donors', recipients', allografts', and surgery data that were related to the occurrence of DGF were recorded from medical records. Serum creatinine concentrations, urine volume, need for dialysis, blood biochemistries, and cell counts of transplant recipients were recorded during hospitalization and after that monthly up to 3 months after transplantation.

\section{Statistical analysis}

Data analysis was performed with SigmaPlot 12.3 (Systat Software, San Jose, CA). The Shapiro-Wilk test was used to assess the normality of the quantitative data. Results are reported as mean $\pm \mathrm{SD}$ or median (minimum-maximum). The $t$ test or Mann-Whitney $U$ test was performed to compare normally and not-normally distributed quantitative variables between the two groups of the study, respectively. Qualitative data were compared using the chi-square or Fisher test. $P<0.05$ was considered statistically significant.

\section{Results}

During the study period, 39 transplants were performed at our center; of them, twenty patients were randomized between the two arms of the study. In the vitamin $\mathrm{C}$ group, nine patients completed the study period, and one patient withdrew due to shortness of breath and fatigue after infusion of one-third of vitamin $\mathrm{C}$ solution. In the placebo group, all ten patients completed the entire study period (Fig. 1). Basic information regarding donors, recipients, and allograft are summarized in Table 1 . As seen, these data were not significantly different between the two 


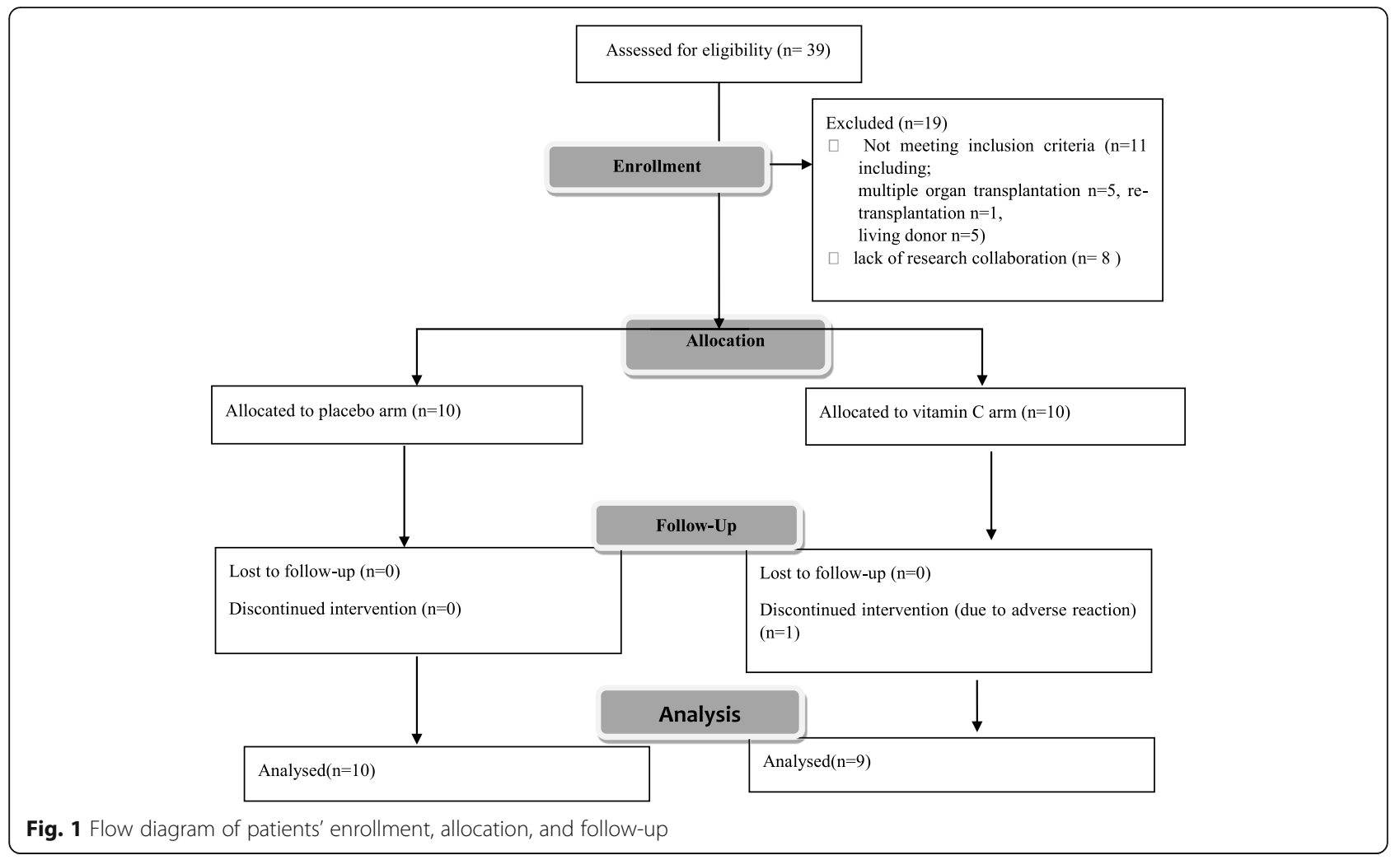

groups of the study, except for the donor age which is borderline significant $(P=0.047)$. HLA-typing and donorspecific antibodies (DSAs) in the case of deceased-donor kidney transplantation are not available at our center.

The primary and secondary outcomes of the study are summarized in Table 2. DGF incidence did not differ between the vitamin $C$ and placebo groups based on both dialysis criteria and all criteria mentioned in the method section. However, the DGF duration was significantly shorter in the vitamin $C$ group $(P=0.02)$. Secondary outcomes including eGFR, serum creatinine concentrations, rejection episodes, and hospitalization duration did not differ between groups. The frequency of acute rejection was $66.6 \%$ in the vitamin $C$ group and $40 \%$ in the placebo group. Both groups had the same number AMR and TCMR. In the vitamin $C$ group, two episodes of mixed rejection occurred, but the patients in the placebo arm did not experience this type of acute rejection. Although this difference was not statistically significant due to safety concerns, the study was terminated. Except for the excluded patient from the vitamin $C$ group, others did not develop any adverse effect during the study follow-up.

\section{Discussion}

This preliminary study on 19 patients ( 9 cases in the vitamin $\mathrm{C}$ group and 10 cases in the placebo group) showed that after administration of single, high dose vitamin $C$ the incidence of DGF was not significantly different between the groups, but the duration of DGF was substantially shorter in the vitamin $C$ group than the placebo group.

Lee et al. showed that long-term outcomes of kidney function did not differ between recipients without DGF and those who recovered from DGF [27]. Therefore, in addition to reducing the occurrence of DGF, assisting its recovery, and reducing the severity of this complication may affect long-term renal outcomes. On the other hand, some reasons may elucidate the failure of vitamin $\mathrm{C}$ to reduce the incidence of DGF in this study. Vitamin C prooxidant property [28] can be a justification for its ineffectiveness in reducing DGF occurrence. Also, premature termination of trial and low sample size may be another reason for failing to achieve the primary result.

One patient in vitamin $C$ arm developed a reaction during vitamin $C$ infusion as it has been described in the "Result" section. At the time of these complications, the patient was not impaired in vital signs and hemodynamic parameters and does not fall into the category of serious complications. Also, the adverse effect severity based on Modified Hartwig and Siegel scale is at level two describes as the adverse drug reaction (ADR) requires that treatment with the suspected drug be held, discontinued, or otherwise changed. No antidote or other treatment required. No increase in the length of hospital stay [29]. Given that re-administration of vitamin $\mathrm{C}$ has not been 
Table 1 Baseline characteristics of donors, recipients, and organs

\begin{tabular}{|c|c|c|c|}
\hline Characteristic & Vitamin C arm $(n=9)$ & Placebo arm $(n=10)$ & $P$ \\
\hline \multicolumn{4}{|l|}{ Recipients } \\
\hline Age (years) & $33.33 \pm 14.59$ & $45.20 \pm 11.03$ & 0.06 \\
\hline Sex (female), $n(\%)$ & $3(33.3)$ & $5(50)$ & 0.65 \\
\hline $\mathrm{BMI}{ }^{\mathrm{a}}\left(\mathrm{kg} / \mathrm{m}^{2}\right)$ & $22.10(15.5-29.4)$ & $21.65(19.1-25.4)$ & 0.96 \\
\hline Cause of ESKD ${ }^{\mathrm{b}}, n(\%)$ & & & 0.27 \\
\hline Hypertension & $2(22.2)$ & $1(10.0)$ & \\
\hline Diabetes mellitus & $2(22.2)$ & 0 & \\
\hline Glomerulonephritis & $2(22.2)$ & $2(20.0)$ & \\
\hline $\mathrm{PKD}^{\mathrm{C}}$ & 0 & $2(20.0)$ & \\
\hline Drug-induced & 0 & $2(20.0)$ & \\
\hline Other causes & $3(33.3)$ & $3(30.0)$ & \\
\hline Type of dialysis, $n$ (\%) & & & 0.08 \\
\hline Hemodialysis & $6(66.7)$ & $10(100.0)$ & \\
\hline Peritoneal dialysis & $3(33.3)$ & 0 & \\
\hline Duration of dialysis (months) & $24(6-42)$ & $20(5-240)$ & 0.83 \\
\hline History of blood transfusion, $n(\%)$ & $7(77.8)$ & $8(80.0)$ & 0.58 \\
\hline PRA $^{d}(\%)$ & 0 & 0 & $>0.99$ \\
\hline 24-h residual diuresis (ml) & $200(0-1500)$ & $350(0-1500)$ & $>0.99$ \\
\hline \multicolumn{4}{|l|}{ Donors } \\
\hline Age (years) & $27.89 \pm 10.79$ & $39.00 \pm 11.74$ & 0.047 \\
\hline Sex (female), $n(\%)$ & $4(44.4)$ & $2(20)$ & 0.35 \\
\hline BMI $\left(\mathrm{kg} / \mathrm{m}^{2}\right)$ & $24.14 \pm 2.24$ & $27.30 \pm 4.78$ & 0.092 \\
\hline $\mathrm{CPR}^{\mathrm{e}}, n(\%)$ & $3(33.3)$ & $2(20.0)$ & 0.62 \\
\hline Hypertension, $n$ (\%) & 0 & $1(10.0)$ & $>0.99$ \\
\hline Diabetes mellitus, $n(\%)$ & 0 & 0 & $>0.99$ \\
\hline $\mathrm{SCr}{ }^{f}(\mathrm{mg} / \mathrm{dL})$ & $1.23 \pm 0.27$ & $1.14 \pm 0.29$ & 0.51 \\
\hline Last eGFR before donation $\left(\mathrm{ml} / \mathrm{min} / 1.73 \mathrm{~m}^{2}\right)$ & $69.70(48.40-90.60)$ & $78.30(45.59-198.0)$ & 0.36 \\
\hline$E C D^{h}, n(\%)$ & 0 & 0 & $>0.99$ \\
\hline Length of ICU stay (days) & $3(1-5)$ & $4(1-15)$ & 0.28 \\
\hline \multicolumn{4}{|l|}{ Transplantation } \\
\hline Duration of surgery (min) & $210(195-300)$ & $210(180-360)$ & 0.27 \\
\hline Cold ischemic time (min) & $195.56 \pm 77.35$ & $221.30 \pm 70.45$ & 0.45 \\
\hline ABO incompatibility, $n$ (\%) & 0 & 0 & $>0.99$ \\
\hline
\end{tabular}

Data have been presented as mean \pm SD, median (minimum-maximum), or the number of patients (\%) as indicated

${ }^{\mathrm{a}} \mathrm{BMI}$ body mass index

${ }^{\mathrm{b}} E S K D$ end-stage kidney disease

${ }^{C} P K D$ polycystic kidney disease

${ }^{\mathrm{d}} P R A$ panel-reactive antibody

${ }^{e} C P R$ cardiopulmonary resuscitation

${ }^{f} E C D$ expanded criteria donor

${ }^{g}$ eGFR estimated glomerular filtration rate

${ }^{\mathrm{h}} \mathrm{SCr}$ serum creatinine concentration

performed to evaluate the re-occurrence of the reaction, causality assessment of this complication cannot be accurately commented. Also, other patients did not experience such complications. However, based on the Naranjo causality assessment criterion [30], the probability of developing this complication as a result of treatment is in the possible class.

The statistically non-significant difference in acute rejection episodes caused the early discontinuation of the present study due to safety concerns. Vitamin C has 
Table 2 Outcomes of kidney transplantation

\begin{tabular}{|c|c|c|c|}
\hline Outcome & Vitamin C arm $(n=9)$ & Placebo arm $(n=10)$ & $P$ \\
\hline \multicolumn{4}{|l|}{ Primary } \\
\hline DGFa, dialysis criteria, $n(\%)$ & $1(11.1)$ & $1(10.0)$ & $>0.99$ \\
\hline DGFa, urine output criteria, $n(\%)$ & $1(11.1)$ & $2(20.0)$ & $>0.99$ \\
\hline $\mathrm{DGF}^{\mathrm{a}}$, Scr trend criteria, $n(\%)$ & $2(22.2)$ & $2(20.0)$ & $>0.99$ \\
\hline DGF, any criteria, $n(\%)$ & $3(33.3)$ & $3(30.0)$ & $>0.99$ \\
\hline DGF duration (days) & $7.33 \pm 5.68$ & $19.66 \pm 0.57$ & 0.02 \\
\hline eGFR ${ }^{b}$ at discharge $\left(\mathrm{ml} / \mathrm{min} / 1.73 \mathrm{~m}^{2}\right)$ & $55.80 \pm 21.14$ & $52.02 \pm 11.71$ & 0.63 \\
\hline eGFR 1 month after transplantation $\left(\mathrm{ml} / \mathrm{min} / 1.73 \mathrm{~m}^{2}\right)$ & $52.0(18.9-84.4)$ & $47.2(36.0-85.5)$ & 0.71 \\
\hline eGFR 2 months after transplantation $\left(\mathrm{ml} / \mathrm{min} / 1.73 \mathrm{~m}^{2}\right)$ & $46.05 \pm 16.2$ & $60.6 \pm 16.6$ & 0.08 \\
\hline eGFR 3 months after transplantation $\left(\mathrm{ml} / \mathrm{min} / 1.73 \mathrm{~m}^{2}\right)$ & $55.75 \pm 18.23$ & $60.01 \pm 16.49$ & 0.30 \\
\hline $\mathrm{SCr}^{\mathrm{c}}$ at discharge $(\mathrm{mg} / \mathrm{dL})$ & $1.3(1.1-3)$ & $1.4(1-2.1)$ & 0.56 \\
\hline $\mathrm{SCr} 1$ month after transplantation (mg/dL) & $1.6(1.0-2.9)$ & $1.3(0.8-1.9)$ & 0.34 \\
\hline $\mathrm{SCr} 2$ months after transplantation (mg/dL) & $1.7(1.2-2.8)$ & $1.22(0.8-1.6)$ & 0.009 \\
\hline $\mathrm{SCr} 3$ months after transplantation (mg/dL) & $1.40(1.1-3.08)$ & $1.13(0.9-2)$ & 0.07 \\
\hline \multicolumn{4}{|l|}{ Secondary } \\
\hline Hospitalization duration (days) & $14(9-48)$ & $18(8-32)$ & 0.87 \\
\hline Total acute rejection, $n(\%)$ & $6(66.6)$ & $4(40.0)$ & 0.37 \\
\hline $\mathrm{AMR}^{\mathrm{d}}, n(\%)$ & $2(22.2)$ & $2(20.0)$ & $>0.99$ \\
\hline TCMR $^{\mathrm{e}}, n(\%)$ & $2(22.2)$ & $2(20.0)$ & $>0.99$ \\
\hline Mixed rejection episode, $n$ (\%) & $2(22.2)$ & 0 & 0.21 \\
\hline Time to first rejection (days) & $10(5-72)$ & $11.5(5-18)$ & 0.78 \\
\hline
\end{tabular}

Data have been presented as mean \pm SD, median (minimum-maximum), or the number of patients (\%) as indicated

${ }^{a} D G F$ delayed graft function

${ }^{\mathrm{b}}$ eGFR estimated glomerular filtration rate

'SCr serum creatinine concentration

${ }^{\mathrm{d}} A M R$ antibody-mediated rejection

${ }^{\mathrm{e}} T C M R$ T cell-mediated rejection

effects on various components of the immune system. There are evidences regarding both immune-enhancing and immune-modulatory effects of this micronutrient. Its immune enhancer effect is increasing $\mathrm{T}$ lymphocyte proliferation and function [31]. The effect of vitamin C on B lymphocytes is inconsistent [31,32]. On the opposite hand, the effect of vitamin $\mathrm{C}$ on pro-inflammatory factors and reducing tissue damage [9], increasing $\mathrm{T}$ lymphocytes differentiation to regulatory $\mathrm{T}$ cells and subsequent immune tolerance [33] and decrease in interlukine-2 (IL-2) production by lymphocytes [34] are proposed immune-modulatory effects of vitamin C. There is a report of reduced skin transplant rejection with vitamin $\mathrm{C}$ in the animal model by lowering $\mathrm{T}$ helper-17 cell differentiation and increasing regulatory $\mathrm{T}$ differentiation [35]. By putting together all the pieces of the puzzle, due to the different effects of vitamin $\mathrm{C}$ on the various components of the immune system, its interpretation in clinical studies should be performed with careful scrutiny. As far as we know, there has been no report of transplant rejection due to vitamin C. Most studies investigating the effect of vitamin $\mathrm{C}$ on transplant recipients often have used low doses and oral route of administration. The highest dose of vitamin $\mathrm{C}$ used in transplant patients before the present survey is a study published in 1983 in which kidney transplant patients consumed $4 \mathrm{~g}$ of vitamin $\mathrm{C}$ daily. In this study, patients with stable allograft function at least 3 months after transplantation were compared with healthy volunteers for granulocyte adhesion. The authors did not indicate the transplant rejection rate [36]. The use of oral doses and the inclusion of patients that passed the most common transplant rejection period, i.e., the first 3 months, may make a difference in the results of that study compared to our research.

In this study, for the first time, the effect of a single high-dose of vitamin $C$ infusion was investigated among kidney transplant recipients hoping a low-cost and accessible treatment could reduce DGF duration. Also, instead of complications such as nephropathy, which have been reported repeatedly as vitamin $\mathrm{C}$ adverse effect, attention has been focused on the immunological effects of vitamin C. However, the study also had its limitations. Important limitations of this study are the low sample 
size, non-implementation of biopsy protocol in the treatment center, and lack of access to the immunological compatibility of the transplant donor and recipient.

\section{Conclusion}

A high dose of intravenous vitamin $\mathrm{C}$ before allograft implantation was effective in decreasing DGF duration but not DGF incidence. The number of acute rejection episodes was slightly higher in the vitamin $C$ group, but it was not statistically significant. This inter-group difference raised safety concerns and resulted in premature termination of the trial. Given the results of this study and the complex effects of vitamin $\mathrm{C}$ on the immune system, it is prudent to test the effect of high dose vitamin $\mathrm{C}$ on allograft rejection or acceptance in more experimental models before other human studies.

\section{Abbreviations}

BPAR: Biopsy-proven acute rejection; BMI: Body mass index; DGF: Delayed graft function; DSAs: Donor-specific antibodies; eGFR: estimated Glomerular Filtration Rate; IL-2: InterLukine-2; IRI: Ischemia-reperfusion injury; MDRD: Modification of diet in renal disease; rATG: rabbit Anti-Thymocyte Globulin; ROS: Reactive oxygen species

\section{Acknowledgements}

This study was a part of a clinical pharmacy residency thesis supported by Tehran University of Medical Sciences. We sincerely thank the head, staff, and nurses of the kidney transplantation ward of Imam-Khomeini Hospital Complex for providing the research and cooperation platform.

\section{Authors' contributions}

Research conception and design: Simin Dashti-Khavidaki, Mina Borran. Data acquisition: Mina Borran, Simin Dashti-Khavidaki, Azam Alamdari, Neda Naderi, Farzanehsadat Minoo. Statistical analysis: Mina Borran, Simin DashtiKhavidaki. Data analysis and interpretation: Mina Borran, Simin DashtiKhavidaki, Azam Alamdari, Neda Naderi, Farzanehsadat Minoo. Drafting of the manuscript: Mina Borran, Simin Dashti-Khavidaki. Critical revision of the manuscript: Mina Borran, Simin Dashti-Khavidaki, Azam Alamdari, Neda Naderi, Farzanehsadat Minoo. Administrative, technical, or material support: Mina Borran, Simin Dashti-Khavidaki, Azam Alamdari, Neda Naderi, Farzanehsadat Minoo. Supervision: Mina Borran, Simin Dashti-Khavidaki. Approval of the final manuscript: Mina Borran, Simin Dashti-Khavidaki, Azam Alamdari, Neda Naderi, Farzanehsadat Minoo.

\section{Funding}

This study was a part of a clinical pharmacy residency thesis from Tehran University of Medical Sciences. There is no funding support.

\section{Availability of data and materials}

The datasets analyzed during the current study are available from the corresponding author on reasonable request.

\section{Ethics approval and consent to participate}

All precipitants signed a written consent form. Also, the study protocol was approved by the local ethics committee of Tehran University of Medical Sciences (IR.TUMS.TIPS.REC.1398.007)

\section{Competing interests}

The authors declare no conflict of interest.

\section{Author details}

${ }^{1}$ Faculty of Pharmacy, Tehran University of Medical Sciences, P.O.Box 1417614411, Tehran, Iran. ${ }^{2}$ Nephrology Research Center, Tehran University of Medical Sciences, Tehran, Iran.
Received: 11 March 2020 Accepted: 29 June 2020

Published online: 08 July 2020

\section{References}

1. Yarlagadda SG, Coca SG, Garg AX, Doshi M, Poggio E, Marcus RJ, et al. Marked variation in the definition and diagnosis of delayed graft function: a systematic review. Nephrol Dial Transplant. 2008;23(9):2995-3003.

2. Bahl D, Haddad Z, Datoo A, Qazi YA. Delayed graft function in kidney transplantation. Curr opin in organ transplant. 2019;24(1):82-6.

3. Nashan B, Abbud-Filho M, Citterio F. Prediction, prevention, and management of delayed graft function: where are we now? Clin Transpl. 2016;30(10):1198-208.

4. Chaumont M, Racapé J, Broeders N, El Mountahi F, Massart A, Baudoux T, et al. Delayed graft function in kidney transplants: time evolution, role of acute rejection, risk factors, and impact on patient and graft outcome. J Transp Secur. 2015;2015.

5. Irish WD, McCollum DA, Tesi RJ, Owen AB, Brennan DC, Bailly JE, et al. Nomogram for predicting the likelihood of delayed graft function in adult cadaveric renal transplant recipients. Clin J Am Soc Nephrol. 2003;14(11): 2967-74.

6. Salvadori M, Rosso G, Bertoni E. Update on ischemia-reperfusion injury in kidney transplantation: pathogenesis and treatment. World J Transplant. 2015;5(2):52

7. Zhao H, Alam A, Soo AP, George AJ, Ma D. Ischemia-reperfusion injury reduces long term renal graft survival: mechanism and beyond. EBioMedicine. 2018;28:31-42.

8. Dirksen MT, Laarman GJ, Simoons ML, Duncker DJGM. Reperfusion injury in humans: a review of clinical trials on reperfusion injury inhibitory strategies. Cardiol Res. 2007;74(3):343-55.

9. Spoelstra-de Man AM, Elbers PW, Oudemans-Van Straaten HM. Vitamin C. should we supplement? Curr Opin Crit Care. 2018;24(4):248

10. Spoelstra-de Man AM, Elbers PW, Oudemans-van Straaten HM. Making sense of early high-dose intravenous vitamin $C$ in ischemia/reperfusion injury. Crit Care. 2018;22(1):70.

11. Korkmaz A, Kolankaya D. The protective effects of ascorbic acid against renal ischemia-reperfusion injury in male rats. Ren Fail. 2009;31(1):36-43.

12. Syed AA, Knowlson S, Sculthorpe R, Farthing D, DeWilde C, Farthing CA, et al. Phase I safety trial of intravenous ascorbic acid in patients within the treatment of sepsis. J Transl Med. 2014:12(1):32.

13. Fang JC, Kinlay S, Beltrame J, Hikiti H, Wainstein M, Behrendt D, et al. Effect of vitamins $C$ and $E$ on progression of transplant-associated arteriosclerosis: a randomised trial. Lancet. 2002;359(9312):1108-13.

14. Williams MJ, Sutherland WH, McCormick MP, de Jong SA, McDonald JR, Walker RJ. Vitamin C improves endothelial dysfunction in renal allograft recipients. Nephrol Dial Transplant. 2001;16(6):1251-5.

15. Loong C, Chang Y, Wu T, King K, Yang W, Wu C, et al., editors. Antioxidant supplementation may improve renal transplant function: a preliminary report. Transplant Proc. 2004; 2004.

16. Rabl H, Khoschsorur $G$, Colombo T, Petritsch $P$, Rauchenwald M, Költringer $P$, et al. A multivitamin infusion prevents lipid peroxidation and improves transplantation performance. Kidney Int. 1993;43(4):912-7.

17. Varghese Z, Fernando RL, Turakhia G, Psimenou E, Fernando ON, Sweny P, et al. Calcineurin inhibitors enhance low-density lipoprotein oxidation in transplant patients. Kidney Int. 1999:56:S137-40.

18. Sahraei Z, Salamzadeh J, Nafar M. Effect of N-acetyl cysteine and vitamin C on kidney allograft function biomarkers interleukin-18 and neutrophil gelatinase-associated lipocalin. Iran J Kidney Dis. 2015;9(1):56.

19. Ma Y, Chapman J, Levine M, Polireddy K, Drisko J, Chen Q. High-dose parenteral ascorbate enhanced chemosensitivity of ovarian cancer and reduced toxicity of chemotherapy. Sci Transl Med. 2014;6(222):222ra18-ra18.

20. Khoshnam-Rad N, Khalili H. Safety of vitamin C in sepsis: a neglected topic. Curr Opin Crit Care. 2019;25(4):329-33.

21. Lee SWH, Lai NM, Chaiyakunapruk N, Chong DWK. Adverse effects of herbal or dietary supplements in G6PD deficiency: a systematic review. Br J Clin Pharmacol. 2017:83(1):172-9.

22. La Vieille S, Lefebvre DE, Khalid AF, Decan MR, Godefroy S. Dietary restrictions for people with glucose-6-phosphate dehydrogenase deficiency. Nutr Rev. 2018;77(2):96-106.

23. Marik PE. Is intravenous vitamin C contraindicated in patients with G6PD deficiency? BMC Med. 2019;23:109. 
24. Shaikh H, Faisal MS, Mewawalla P. Vitamin C deficiency: rare cause of severe anemia with hemolysis. Int J Hematol. 2019;109(5):618-21.

25. Sotomayor CG, Eisenga MF, Gomes Neto AW, Ozyilmaz A, Gans RO, De Jong WH, et al. Vitamin C depletion and all-cause mortality in renal transplant recipients. Nutrients. 2017;9(6):568.

26. Fowler AA 3rd, Syed AA, Knowlson S, Sculthorpe R, Farthing D, DeWilde C, et al. Phase I safety trial of intravenous ascorbic acid in patients with severe sepsis. J Transl Med. 2014;12:32.

27. Lee J, Song SH, Lee JY, Kim DG, Lee JG, Kim BS, et al. The recovery status from delayed graft function can predict long-term outcome after deceased donor kidney transplantation. Sci Rep. 2017;7(1):13725.

28. Tóth SZ, Lörincz T, Szarka A. Concentration does matter: the beneficial and potentially harmful effects of ascorbate in humans and plants. Antioxid Redox Signal. 2018;29(15):1516-33.

29. Hartwig SC, Siegel J, Schneider PJ. Preventability and severity assessment in reporting adverse drug reactions. Am J Hosp Pharm. 1992;49(9):2229-32.

30. Liang R, Borgundvaag B, McIntyre M, Thwaites C, Ragan K, Wyllie A. Evaluation of the reproducibility of the Naranjo adverse drug reaction probability scale score in published case reports. Pharmacotherapy. 2014; 34(11):1159-66.

31. Van Gorkom GN, Klein Wolterink RG, Van Elssen CH, Wieten L, Germeraad WT, Bos GM. Influence of vitamin C on lymphocytes: an overview. Antioxidants. 2018;7(3):41.

32. Prinz W, Bortz R, Bregin B, Hersch M. The effect of ascorbic acid supplementation on some parameters of the human immunological defence system. Int J Vitam Nutr Res. 1977:47(3):248-57.

33. Sakaguchi S, Yamaguchi T, Nomura T, Ono M. Regulatory T cells and immune tolerance. Cell. 2008;133(5):775-87.

34. Härtel C, Strunk T, Bucsky P, Schultz C. Effects of vitamin C on intracytoplasmic cytokine production in human whole blood monocytes and lymphocytes. Cytokine. 2004;27(4-5):101-6.

35. Nikolouli E, Hardtke-Wolenski M, Hapke M, Beckstette M, Geffers R, Floess S, et al. Alloantigen-induced regulatory T cells generated in presence of vitamin C display enhanced stability of Foxp3 expression and promote skin allograft acceptance. Front Immunol. 2017;8:748.

36. Thorner RE, Barker CF, MacGregor RR. Improvement of granulocyte adherence and in vivo granulocyte delivery by ascorbic acid in renal transplant patients. Transplantation. 1983;35(5):432-6.

\section{Publisher's Note}

Springer Nature remains neutral with regard to jurisdictional claims in published maps and institutional affiliations.

Ready to submit your research? Choose BMC and benefit from:

- fast, convenient online submission

- thorough peer review by experienced researchers in your field

- rapid publication on acceptance

- support for research data, including large and complex data types

- gold Open Access which fosters wider collaboration and increased citations

- maximum visibility for your research: over $100 \mathrm{M}$ website views per year

At $\mathrm{BMC}$, research is always in progress.

Learn more biomedcentral.com/submissions 